\title{
Study on Efficiencies of Skidding Stems and Loading Logs Based on Multifunctional Skidding Loader
}

\author{
Deling Yang, Wenshu Lin, Jinzhuo Wu, Lihai Wang* \\ Key Laboratory of Forest Sustainable Management and Environmental \\ Microorganism Engineering of Heilongjiang Province \\ Northeast Forestry University \\ Harbin, China \\ Yangdeling1979@126.com, *Corresponding author: lihaiwang@yahoo.com
}

\begin{abstract}
The efficiency of skidding stems and loading logs was investigated in Daxin forest farm, Linjiang Forest Bureau, Jilin Forest Industry Group by using a loader together with a winch and retaining plate. During skidding operations, the average of skidding distance and time are $86.15 \mathrm{~m}$ and 9.68 minute, respectively, the average of skidding quantity and number of stems per skidding circle is $1.12 \mathrm{~m}^{3}$ and 3 . The productivity of skidding is $29.62 \mathrm{~m}^{3}$ per machine team. During loading operations, the average of loading time is 2.93 minute, respectively, the average of loading quantity and number of logs per loading circle is $0.78 \mathrm{~m}^{3}$ and 5.1, the productivity of loading is $52.6 \mathrm{~m}^{3} \mathrm{per}$ machine team. The regression results show that the skidding efficiencies reduced with increasing skidding time and skidding distance. However, the relationships between skidding efficiencies and skidding quantity per skidding circle were not evident. The correlation results show that skidding efficiency is significantly different among skidding distance, skidding time, skidding quantity per skidding circle, interaction between skidding distance and time, interaction between skidding quantity and numbers of stem or log. The production rate of tracked tractor is higher than wheeled tractor no matter stem or log skidding operations.
\end{abstract}

Keywords: multifunctional skidding loader; skidding; loading; efficiency

\section{Introduction}

In the forest harvesting operation, the production of felling area includes three processes: felling, skidding and loading. The skidding operation is the operation process of collecting and transporting timbers in felling area to wood deport or loading place on mountain. It is an important part of the timber production in fell area. Choosing reasonable skidding operation mode relates to the production efficiency of felling area and the cost of timber production, and influences the regeneration and environmental protection of forests [1]. The loading operation in felling area refers to the operation of loading timbers (stems and logs) in loading place or wood depot onto log transportation vehicles. It is intermediate link between production and transportation of felling area. It can directly influence the efficiency timber transportation machinery, and thus influence the production cost and productivity of timber transportation [2]. As the forest harvesting operation in our country has the new features of scattered operation places, big gradient, sparse trees, low skidding quantity per hectare and 
low log output per standing tree, the utilization of existing large skidding tractors such as J$50, \mathrm{~J}-80$ and other machines for skidding operation and cableway or high platform and fixed hack lever for loading has exclusively used for forestry, which will cause big auxiliary workload, too many processes, low efficiency, high cost and great damage to environment. Therefore, we need to explore the new, small, flexible and environment-friendly skidding and loading machinery more suitable for the production reality of forest area [3-5].

The principal parameters for the loader with multifunctional skidding technology to be design were selected and determined according to the actual survey on the Daxi Forest Farm of Linjiang Forestry Bureau of Jilin Forest Industry Group and the existing research. Based on the principal parameters, the reconstruction design for ZLY925D loader produced by Shandong Shiliyuan Engineering Machinery Co., Ltd. was carried out, the design and check of timber gripper was carried out, the specialized winch, carrying board and other kinds of equipment were added, and the winch and carrying board and the sample skidding loader were linked together at last. After the design and reconstruction of the sample skidding loader was completed, the test was carried out in Daxi Forest Farm, Linjiang Forestry Bureau, Jilin Forest Industry Group. This paper focus on researching the production efficiency of skidding and loading operation of the designed multifunctional skidding and loading machine, in order to compare it with other mobile multifunctional skidding and loading machines, and thus verifies that the designed multifunctional forestry equipment used for the skidding and loading operation of the forest area in Northeast China can improve the timber production efficiency, reduce the production cost, reduce the labor and resource consumption, solve the actual problem of timber production, promote the modernization of forestry machinery, drive the economic growth of forest area, play an significant role in accelerating the forestry development and forest construction, and achieving the sustainable management of forest.

\section{Research Area and Operation Condition}

The selected experimental plots were located in the Daxi Forest Farm, Linjiang Forestry Bureau, Jilin Forest Industry Group. This area is characterized by temperate monsoon climate, cold and snowy in winter, warm and rainy in summer with annual average rainfall of $660 \mathrm{~mm}$. Average annual temperature is $1.3^{\circ} \mathrm{C}$, frost-free period is about 115 days, and the soil is Dark Brown forest soil. The skidding field belongs to No.1 subcompartment of No.58 compartment in Daxi forest farm with area of $10.9 \mathrm{hm}^{2}$. The altitude of the site is $670 \mathrm{~m}$, slope faces West-south and the average slope gradient is $6^{\circ} \sim 8^{\circ}$. The average depth of the soil is $20 \mathrm{~cm}$. For middle coverage degree Equisetum as its vegetation cover, and heavy coverage degree Acer ukurunduense as its shrubbery. This is a man-made forest with mixed softwoods and hardwoods. The main tree species are Larix gmelinii, Pinus koraiensis, Fraxinus mandshurica Rupr, T.tuan SzyszyL. The average forest age is 48ys, average diameter at breast height $(\mathrm{dbh})$ is $24 \mathrm{~cm}$, average tree height is $18 \mathrm{~m}$, canopy density is 0.9 , and tree volume is $244 \mathrm{~m}^{3} / \mathrm{hm}^{2}$.

The felling method is selective felling operation in the selected plots. The developed multifunctional skidding and loading machine was used to carry out the stem skidding and log loading test in the selected sample plot for test in December 2012. The selected skidding operation area is 12.3 hectares, the output of timber is $83 \mathrm{~m}^{3}$, and the average output is $6.75 \mathrm{~m}^{3} /$ hectare. After the bucking of stems, the average length of log is $4 \mathrm{~m}$, and the load height is $2.8 \mathrm{~m}$. In addition, the design multifunctional skidding and loading machine also has the function of obstacle clearing, so the obstacle clearing test 
was carried out in the selected plot. The obstacle clearing gradient is $6^{\circ}$, and the main obstacle clearing objects include bushes, surface stones, vegetation and a small quantity of stumps. Two obstacle clearing tests were carried out. The first test had the obstacle clearing area of $80 \mathrm{~m}^{2}$, and lasted for 35 minutes. The obstacle clearing area had $100 \mathrm{~m}^{2}$, and lasted for 40 minutes during the second test. The reason of the efficiency was higher in the second test is that the driver could operate the machine more skillfully.

\section{Methods}

\subsection{Skidding Efficiency and Loading Efficiency Data Measured}

In combination with the timber production operation of Linjiang Forestry Bureau, the reasonable design and planning of field test is carried out. The multifunctional skidding and loading machine is used to skid the stems. Then, the produced logs are loaded. During the field test, stopwatch and paper are used to keep record. During the skidding operation, the total time used for each skidding is recorded. The total skidding time includes the winching, transportation, unloading and the haul-back. The total time is called a loop. At same time, the skidding distance, and the skidding quantity per trip are recorded in order to analyze the skidding efficiency of the tested sample machine. The skidding efficiency mentioned in this paper refers to the ration between the skidding quantity per trip and the skidding time. The unit is $\mathrm{m}^{3} \cdot \mathrm{h}^{-1} \cdot \operatorname{trip}^{-1}$ [1]. At last, the relationship between the skidding efficiency and the factors of skidding time, skidding distance, skidding quantity per trip, number of stems skidded and average DBH of stems is discussed, and the main factors influencing the skidding efficiency is analyzed. In addition, the working time, break time, preparation time of worker are also recorded every day for calculating the skidding productivity. The total loading time includes grabbing, lifting, unloading and descending. The loading quantity of each time and the number of logs loaded are recorded during the loading operation. The loading efficiency and productivity formula is the same as the skidding efficiency and productivity in the skidding operation.

\subsection{Data Analysis}

The least square method is used to carry out the regression analysis on the relationship between the skidding efficiency and the factors of skidding distance, skidding time and skidding quantity per trip and the relationship between the loading efficiency and the factors of loading time and load capacity. The least square method is a kind of mathematical optimization method, and it finds the best function matching of a group of data by minimizing the quadratic sum of deviation. The unknown data about the skidding and loading efficiency of the multifunctional skidding and loading machine was obtained, and the quadratic sum of the deviation between the acquired data and the actual data was minimized by using of the least square method.

In addition, this paper also adopts $\mathrm{R}$ statistical software to carry out the data analysis and modeling, and uses the generalized linear model (GLM) to determine the correlation between the skidding efficiency and the factors of skidding distance, skidding time, skidding quantity per trip and number of stems skidded and the correlation between the loading efficiency and the factors of loading time, loading quantity and number of logs. The generalized linear model is the extension of the linear model. The feature is that it does not change the natural metric of data by force and the data can have the structure of nonlinearity and unsteady variance. In order to make the analysis easier, the original data are divided simply. For the skidding operation, the skidding distance consists of 4 groups of $70 \mathrm{~m}, 80 \mathrm{~m}, 90 \mathrm{~m}$ and $100 \mathrm{~m}$; 
the skidding quantity per trip consists of 4 groups of $1.0 \mathrm{~m}^{3}, 1.1 \mathrm{~m}^{3}, 1.2 \mathrm{~m}^{3}$ and $1.3 \mathrm{~m}^{3}$; the skidding time consists of 4 groups of $9 \mathrm{~min}, 10 \mathrm{~min}, 11 \mathrm{~min}$ and $12 \mathrm{~min}$; the number of stems skidded each time consists of 3 groups of 2 stems, 3 stems and 4 stems; the average DBH consists of 3 groups of $21 \mathrm{~cm}, 22 \mathrm{~cm}$ and $23 \mathrm{~cm}$; the gradient consists of 3 groups of $4^{\circ}, 5^{\circ}$ and $6^{\circ}$. For loading operation, the loading time consist of 4 groups of $1 \mathrm{~min}, 2 \mathrm{~min}, 3 \mathrm{~min}$ and $4 \mathrm{~min}$; the loading quantity per each time consists of 4 groups of $0.6 \mathrm{~m}^{3}, 0.7 \mathrm{~m}^{3}, 0.8 \mathrm{~m}^{3}$ and $0.9 \mathrm{~m}^{3}$; the number of logs loaded each time consists of 3 groups of $4 \operatorname{logs}, 5 \operatorname{logs}$ and $6 \operatorname{logs}$.

\section{Results}

\subsection{Stem Skidding}

\subsubsection{Stem Skidding Data}

Use the modified multifunctional skidding and loading machine to skid stems in the operation area, record the time used for different processes of skidding operation on the spot, including the skidding distance, the skidding quantity per trip and the number of stems skidded each time (Table 1).

Table 1 Original Data for Stem Skidding

\begin{tabular}{|c|c|c|c|c|c|c|c|c|c|c|}
\hline \multirow{2}{*}{$\begin{array}{c}\text { Stem } \\
\text { skidding } \\
\text { (No.) }\end{array}$} & \multirow{2}{*}{$\begin{array}{c}\text { Skidding } \\
\text { distance } \\
(\mathrm{m})\end{array}$} & \multirow{2}{*}{$\begin{array}{l}\text { Skidding } \\
\text { quantity } \\
\text { per trip } \\
\left(\mathrm{m}^{3} / \text { trip }\right)\end{array}$} & \multirow{2}{*}{$\begin{array}{c}\text { Average } \\
\text { DBH } \\
(\mathrm{cm})\end{array}$} & \multirow{2}{*}{$\begin{array}{c}\text { Gradient } \\
\left(^{\circ}\right)\end{array}$} & \multirow{2}{*}{$\begin{array}{c}\text { Number } \\
\text { of } \\
\text { stems }\end{array}$} & \multicolumn{5}{|c|}{ Time for processes of skidding operation (min) } \\
\hline & & & & & & Winching & Transport & Unloading & $\begin{array}{c}\text { Hauling } \\
\text { back }\end{array}$ & Total \\
\hline 1 & 68 & 1.24 & 22.03 & 5 & 3 & 3.31 & 2.6 & 0.75 & 1.93 & 8.59 \\
\hline 2 & 73 & 1.04 & 21.2 & 4 & 3 & 3.02 & 2.98 & 0.67 & 2.02 & 8.69 \\
\hline 3 & 94 & 1.14 & 22.4 & 5 & 3 & 4.13 & 3.18 & 0.45 & 3.43 & 11.19 \\
\hline 4 & 98 & 1.18 & 22.5 & 6 & 3 & 5.73 & 3.22 & 0.75 & 1.9 & 11.6 \\
\hline 5 & 79 & 1.2 & 21.2 & 5 & 3 & 2.48 & 3.43 & 0.7 & 2.05 & 8.66 \\
\hline 6 & 89 & 1.04 & 28 & 6 & 2 & 2.88 & 3.09 & 0.83 & 2.31 & 9.11 \\
\hline 7 & 91 & 1.08 & 21.33 & 6 & 3 & 3.62 & 3.22 & 0.65 & 2.52 & 10.01 \\
\hline 8 & 82 & 1.28 & 22.37 & 5 & 3 & 3.46 & 2.75 & 0.63 & 2.01 & 8.85 \\
\hline 9 & 80 & 1.04 & 20.6 & 6 & 3 & 3.22 & 2.73 & 0.7 & 2.02 & 8.67 \\
\hline 10 & 98 & 0.98 & 20.73 & 6 & 3 & 3.64 & 3.88 & 0.78 & 2.59 & 10.89 \\
\hline 11 & 81 & 1.29 & 20.87 & 5 & 4 & 4.62 & 2.62 & 0.9 & 2.08 & 10.22 \\
\hline 12 & 92 & 1.04 & 20.47 & 5 & 3 & 2.98 & 3.16 & 1.07 & 2.61 & 9.82 \\
\hline 13 & 85 & 1.14 & 21.8 & 5 & 3 & 3.22 & 2.82 & 0.7 & 2.12 & 8.86 \\
\hline 14 & 90 & 0.98 & 20.51 & 5 & 3 & 3.16 & 3.02 & 0.83 & 2.51 & 9.52 \\
\hline 15 & 71 & 1.22 & 20.7 & 6 & 3 & 3.12 & 2.63 & 0.73 & 2.08 & 8.56 \\
\hline 16 & 90 & 1.03 & 22.4 & 5 & 3 & 3.18 & 3.14 & 0.92 & 2.33 & 9.57 \\
\hline 17 & 84 & 1.2 & 21.2 & 6 & 3 & 3.01 & 3.02 & 0.82 & 2.11 & 8.96 \\
\hline 18 & 102 & 1.16 & 22.54 & 5 & 3 & 3.84 & 4.24 & 1.01 & 3.29 & 12.38 \\
\hline 19 & 92 & 1 & 20.54 & 5 & 3 & 3.25 & 3.17 & 1.19 & 2.57 & 10.18 \\
\hline 20 & 84 & 1.02 & 20.67 & 6 & 3 & 3.01 & 2.97 & 1.12 & 2.26 & 9.36 \\
\hline Ave. & 86.15 & 1.12 & 21.70 & 5.35 & 3 & 3.44 & 3.09 & 0.81 & 2.34 & 9.68 \\
\hline
\end{tabular}

From the average values in the Table 1, we can see that the average skidding distance is $86.15 \mathrm{~m}$, the average skidding quantity per trip is $1.12 \mathrm{~m}^{3} /$ trip, the average DBH is $21.7 \mathrm{~cm}$, the average gradient is $5.35^{\circ}$, and the average skidding time is $9.68 \mathrm{~min}$ when adopting the 
multifunctional skidding and loading machine to skid stems in this test. From the time for different processes of skidding operation, the time for winching is the longest, and secondly is transportation, and then is the hauling back, and the time for unloading is the shortest. The average time for winching and transportation taking up of the total average time is $36 \%$ and $32 \%$, respectively, and the time for unloading only takes up $8 \%$. The reason of the time for winching is longer in this test maybe the forest area is the selective felling operation area, and the trees are scattered and the skidding operation of the sample machine is also influenced by the uneven terrain of the forest land and the remained trees.

\subsubsection{Regression Analysis on Correlation Between Skidding Efficiency and Skidding Time}

By comparing the main regression models of coefficient, linearity, logarithm, polynomial and power, the suitable of model for the stems skidding efficiency and skidding time of the multifunctional skidding and loading machine designed is the polynomial model in this paper. The determination coefficient $\mathrm{R}^{2}$ under the model is the largest, which means that the ratio between the regression sum of square and the sum of deviation square total is the largest. Based on the least square method, a fitted equation for the stems skidding efficiency and skidding time is $E=0.2758 T^{2}-6.3558 T+42.363$, and he correlation coefficient is $\mathrm{R}^{2}=0.69$. The scatter diagram and the curve of fitted equation about the relation changes between the skidding efficiency and the skidding time are shown as Figure 1. From Figure 1 and the fitted equation, we can see that the skidding efficiency decreases as the skidding time increases.

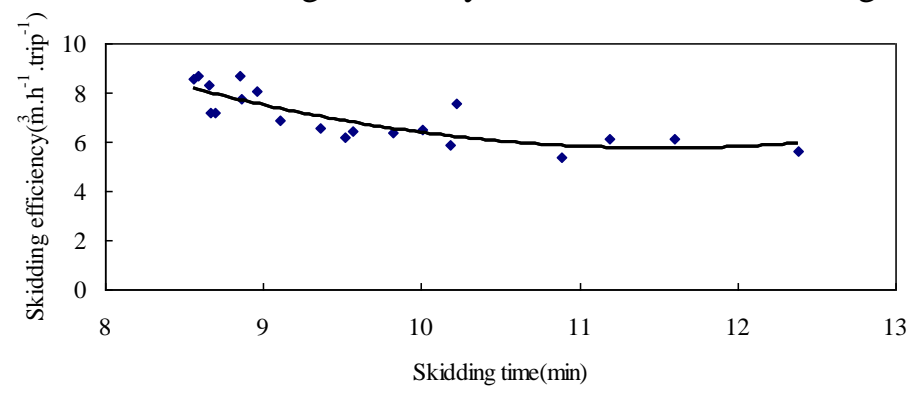

Figure 1 Correlation Between Skidding Efficiency E and Skidding Time T

\subsubsection{Regression Analysis on Correlation Between Skidding Efficiency and Skidding Distance}

According to the least square method, a fitted equation for the stems skidding efficiency and skidding distance is $E=-0.0011 D^{2}+0.0849 D+7.731$, and the correlation coefficient is $\mathrm{R}^{2}=0.73$. The scatter diagram and the curve of fitted equation about the relation changes between the skidding efficiency and skidding distance are shown as Figure 2. From Figure 2 and the fitted equation, we can see that the skidding efficiency decreases as the skidding distance increases. The reason is that the skidding time increases as the skidding distance increases under the situation that the fluctuation of skidding quantity per tip is small, and thus the skidding efficiency becomes lower and lower. 


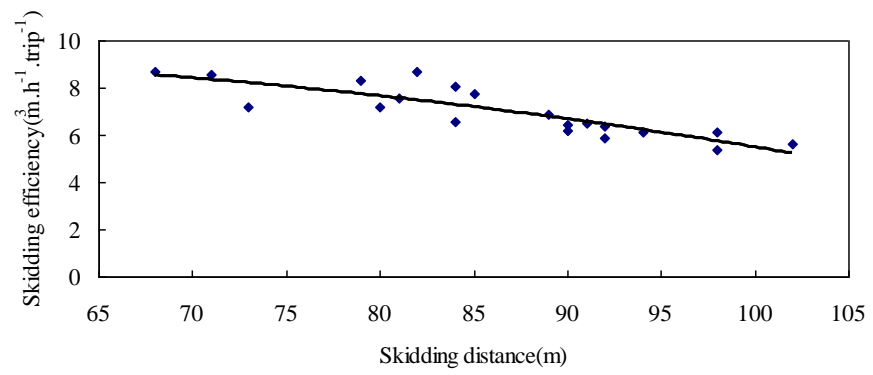

Figure 2. Correlation Between Skidding Efficiency E and Skidding Distance D

\subsubsection{Regression Analysis on Correlation Between Skidding Efficiency and Skidding Quantity Per Trip}

According to the least square method, the fitted equation for the stems skidding efficiency and the skidding quantity per trip is $E=9.8144 Q^{2}-14.907 Q+11.318$, and the correlation coefficient is $R^{2}=0.5$. The scatter diagram about the relation changes between the skidding efficiency and the loading quantity per trip is shown as Figure 3. From Figure 3, we can find that the relation between the skidding quantity per trip and the skidding efficiency is not obvious with the great randomness. The reasons for this maybe that the non-uniformity of whole trunk volume, the change of skidding gradient, the experience in skidding operation of workers and other factors caused.

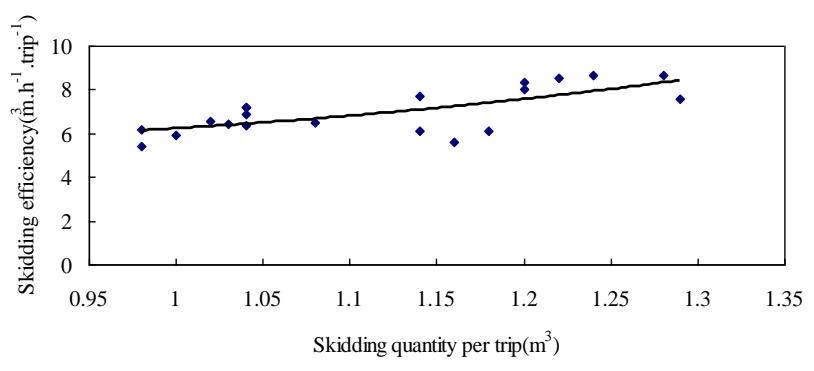

Figure 3 Correlation Between Skidding Efficiency E and Skidding Quantity per Trip Q

\subsubsection{Analysis on Correlation Between Skidding Efficiency and Skidding Time, Distance, Skidding Quantity Per Trip and Number of Stems}

The values measured in the skidding efficiency test, the relation between the multiple target variables (skidding distance, skidding quantity per trip, skidding time, number of stems, DBH of stems and gradient) and the skidding efficiency shall be handled, and there is some correlation between the skidding efficiency and the above variables. If the simple regression method or one of the variables alone is used to explain the question about the skidding efficiency of the skidding loader, there will be some disturbance among the above variables, and the predicted value will not be accurate. Therefore, the general linear model is used to analyze the relation between the skidding efficiency and the above target variables:

$$
E_{i j k m m o}=u+D_{i} * T_{j}+Q_{k} * G_{l}+X_{m}+P_{n}+e_{i j k \text { kno }}
$$

In the formula, where $\mathrm{i}=1,2, \ldots, 4 ; \mathrm{j}=1,2 . \ldots, 4 ; \mathrm{k}=1,2, \ldots, 4 ; \mathrm{l}=1,2, \ldots, 3 ; \mathrm{m}=1,2$, $\ldots, 3 ; \mathrm{n}=1,2, \ldots, 3 ; \mathrm{o}=1,2, \ldots, \mathrm{s} ; \mathrm{E}_{\mathrm{ijklmno}}$ represents the oth observation of skidding 
efficiency of the skidding and loading machine; $u$ represents the mean of each response variable; i represents the ith effect of skidding distance; $j$ represents the jth effect of skidding time; $\mathrm{k}$ represents the kth effect of skidding quantity per trip; 1 represents the lth effect of number of stems skidded per trip; $m$ represents the mth effect of stem $\mathrm{DBH} ; \mathrm{n}$ represents the nth effect of gradient; $e_{i j k l m n o}$ means an error component that represents uncontrolled variability; s represents the number of observations within each treatment. Meanwhile, the model also takes the interaction factors between skidding distance and skidding time as well as skidding quantity per trip and number of stems skidded into consideration.

Based on the result statistical analysis, the skidding efficiency of the multifunctional skidding and loading machine is significantly different in the skidding distance $(P<0.001)$, the skidding time $(P<0.001)$, the skidding quantity per trip $(P<0.01)$ and the correlation between skidding distance and skidding time. But the correlations between skidding efficiency and number of stems skidded $(P=0.63)$, skidding efficiency and stems DBH $(P=0.28)$, skidding efficiency and gradient $(P=0.79)$ as well as skidding efficiency and skidding quantity per trip and number of stems skidded have no significant difference. The reasons maybe that the changes of number of stems skidded, the DBH and gradient in this skidding operation test, the influence on the skidding efficiency is not so obvious. After removing the variables which have no significant difference with the skidding efficiency, the general linear model for correlation between the new skidding efficiency of the skidding loader and the skidding distance, the skidding time and the skidding quantity per trip is $E=14.32-0.0835 D-1.588 T+6.572 Q+0.0094 D * T$, and $\mathrm{R}^{2}$ is 0.9 . From this model, we can find that the skidding efficiency decreases as the skidding distance and the skidding time increase. However, the skidding efficiency increases as the skidding quantity per trip increases.

\subsubsection{Analysis on Skidding Productivity}

There are many factors influencing the skidding productivity, including features of standing forest, topographic conditions, weather and other natural factors. The skidding productivity is also influenced by mechanical equipment, laborers, production organization and other social and technological factors [6-7]. The skidding productivity of the multifunctional skidding and loading machine studied in this paper can be calculated with the following formula [8]:

$$
P=\frac{\left(t-t^{\prime}\right) \varphi M}{t_{1}+\frac{60 L}{V_{1}}+t_{2}+\frac{60 L}{V_{2}}}
$$

In the formula, $P$ is the skidding productivity with the unit of $\mathrm{m}^{3} /$ machine. shift; $t$ is the total working time per shift with the unit of $\min ; t^{\prime}$ is the time for preparation before shift and the time for finishing after shift with the unit of min; $\varphi$ is the working time utilization coefficient with the value of $0.75-0.95$ in consideration of rest and individual needs; $M$ is the average skidding quantity per trip with the unit of $\mathrm{m}^{3} ; t_{l}$ is the time for winching with the unit of min; $L$ is the average skidding distance with the unit of $\mathrm{km} ; t_{2}$ is the time for unloading with the unit of min; $V_{l}$ is the average transportation speed of the skidding loader with the unit of $\mathrm{km} / \mathrm{h} ; V_{2}$ is the average hauling back time of the skidding loader with the unit of $\mathrm{km} / \mathrm{h}$.

In the test, the average of working time is 6 hours for each shift per day. The time recorded for preparation before shift and finishing after shit is 40min. the working time utilization coefficient is 0.8. Based on the data listed in Table 1, Formula (2) is used to calculate the stem skidding productivity of the multifunctional skidding and loading machine. The result is listed as below: 


$$
P=\frac{(60 \times 6-40) \times 0.8 \times 1.16}{3.44+3.09+0.81+2.34}=29.62 \mathrm{~m}^{3} / \text { machine } \cdot \text { shift }
$$

\subsection{Log Loading}

\subsubsection{Log Loading Data}

Use the modified multifunctional skidding and loading machine to load the logs in the operation area, record the time used for different processes of loading operation, the loading quantity per trip and the number of logs loaded each time (Table 2).

Table 2 Original Data for Stem Skidding

\begin{tabular}{|c|c|c|c|c|c|c|c|}
\hline \multirow{2}{*}{$\begin{array}{c}\text { Log } \\
\text { loading } \\
\text { (No.) }\end{array}$} & \multirow{2}{*}{$\begin{array}{c}\text { Loading } \\
\text { quantity } \\
\left(\mathrm{m}^{3} / \text { time }\right)\end{array}$} & \multirow{2}{*}{$\begin{array}{l}\text { Number } \\
\text { of logs }\end{array}$} & \multicolumn{5}{|c|}{ Time for processes of loading operation (min) } \\
\hline & & & Grabbing & Lifting & Unloading & Descending & Total \\
\hline 1 & 0.806 & 5 & 1.32 & 0.98 & 1.1 & 0.17 & 3.57 \\
\hline 2 & 0.612 & 4 & 0.92 & 0.37 & 2 & 0.27 & 3.56 \\
\hline 3 & 0.836 & 5 & 1.53 & 1.12 & 1.05 & 0.21 & 3.91 \\
\hline 4 & 0.914 & 6 & 1.62 & 1.43 & 0.78 & 0.23 & 4.06 \\
\hline 5 & 0.742 & 5 & 1.25 & 1.07 & 0.98 & 0.19 & 3.49 \\
\hline 6 & 0.824 & 5 & 0.95 & 1.02 & 0.68 & 0.18 & 2.83 \\
\hline 7 & 0.864 & 6 & 1.06 & 1.23 & 0.92 & 0.31 & 3.52 \\
\hline 8 & 0.796 & 6 & 1.21 & 1.12 & 0.79 & 0.25 & 3.37 \\
\hline 9 & 0.654 & 4 & 0.98 & 0.72 & 0.82 & 0.22 & 2.74 \\
\hline 10 & 0.702 & 5 & 0.86 & 0.68 & 0.54 & 0.18 & 2.26 \\
\hline 11 & 0.826 & 5 & 1.02 & 0.96 & 0.76 & 0.2 & 2.94 \\
\hline 12 & 0.854 & 6 & 1.12 & 0.78 & 0.96 & 0.24 & 3.1 \\
\hline 13 & 0.904 & 6 & 1.22 & 0.8 & 0.58 & 0.21 & 2.81 \\
\hline 14 & 0.822 & 5 & 0.96 & 0.75 & 0.69 & 0.18 & 2.58 \\
\hline 15 & 0.798 & 5 & 0.88 & 0.65 & 0.57 & 0.15 & 2.25 \\
\hline 16 & 0.656 & 4 & 0.76 & 0.54 & 0.48 & 0.19 & 1.97 \\
\hline 17 & 0.734 & 5 & 0.95 & 0.78 & 0.51 & 0.12 & 2.36 \\
\hline 18 & 0.886 & 6 & 1.04 & 0.94 & 0.68 & 0.17 & 2.83 \\
\hline 19 & 0.708 & 5 & 0.99 & 0.72 & 0.58 & 0.16 & 2.45 \\
\hline 20 & 0.602 & 4 & 0.56 & 0.68 & 0.54 & 0.13 & 1.91 \\
\hline Ave. & 0.78 & 5.10 & 1.06 & 0.87 & 0.80 & 0.20 & 2.93 \\
\hline
\end{tabular}

From the average values in Table 2, we can see that the average loading quantity per time is $0.78 \mathrm{~m}^{3}$, the average number of logs loaded per time is 5.1 , and the average loading time is $2.93 \mathrm{~min}$ in this test. From the time for different processes of loading operation, the time for grabbing is longest, and secondly is lifting, then is unloading, and the shortest is descending. The average time for grabbing takes up $36 \%$ of the total average time. Therefore, an effective way to improve the loading efficiency is to reduce the grabbing time of the loading machine.

\subsubsection{Regression Analysis on Correlation Between Loading Efficiency and Loading Time}

The suitable model for the log loading efficiency and the loading time in this paper is the polynomial model. The determination coefficient $\mathrm{R}^{2}$ is the largest, and the corresponding of 
the ratio between the regression sum of square and the sum of deviation square total is the largest. Based on the least square method, the fitted equation for the log loading efficiency and loading time is $E=-0.2994 T^{2}-2.2278 T+25.645$, and the correlation coefficient is $\mathrm{R}^{2}=0.72$. The scatter diagram and the curve of fitted equation about the relation between the loading efficiency changes and the loading time are shown as Figure 4. From Figure 4 and the fitted equation, we can see that the loading efficiency decreases as the loading time increases.

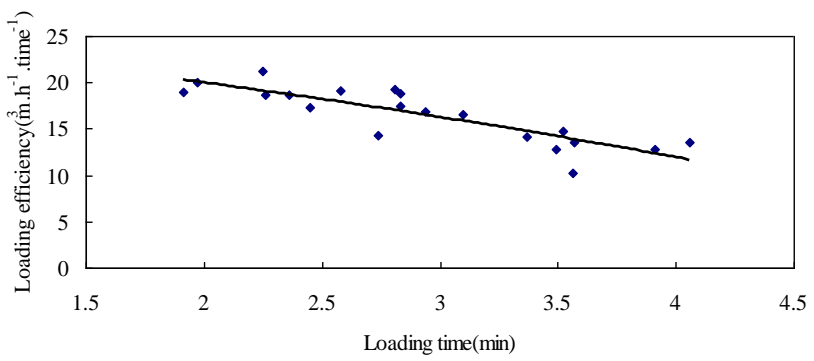

Figure 4 Correlation Between Loading Efficiency E and Loading Time T.

\subsubsection{Regression Analysis on Correlation Between Loading Efficiency and Loading Quantity Per Time}

According to the least square method, the correlation coefficient $\mathrm{R}^{2}$ between the $\log$ loading efficiency and the loading quantity per time is far smaller than 0.5. The scatter diagram about the relation between the loading efficiency and the loading quantity is shown as Figure 5. From the Figure 5, we can see that the relation between the loading quantity and the loading efficiency is not obvious with the big randomness. The reason is that the logs are easy to run around, and cause the non-uniformity when the gripping apparatus grips the logs.

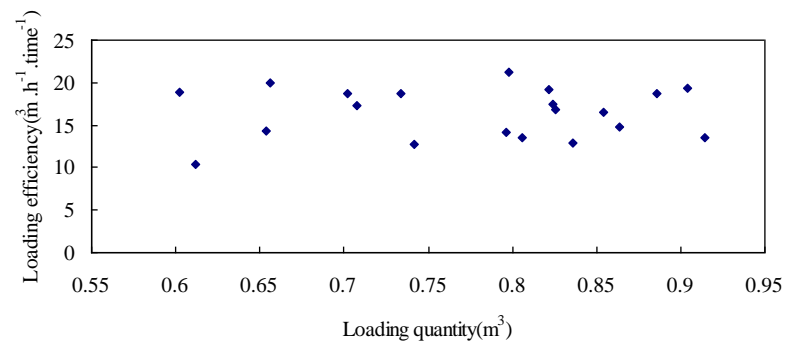

Figure 5. Correlation Between Loading Efficiency E and Loading Quantity Q.

\subsubsection{Analysis on Correlation Between Loading Efficiency and Loading Time, Loading Quantity Per Trip and Number of Logs}

In the log loading efficiency test, the relation between the multiple target variables (loading quantity per time, loading time and number of logs) and the loading efficiency shall be handled, and there is some correlation between the loading efficiency and the above variables. If the simple regression method or one of the variables alone is used to explain the question about the loading efficiency of the loading machine, there will be some disturbance among the above variables, and the predicted value will not be accurate. Therefore, a general linear model is used to analyze the relation between the loading efficiency and the above target variables: 


$$
E_{i j k l}=u+T_{i}+Q_{j}+G_{k}+e_{i j k l}
$$

In the formula, where $\mathrm{i}=1,2, \ldots, 4 ; \mathrm{j}=1,2 . \ldots, 4 ; \mathrm{k}=1,2, \ldots, 3 ; \mathrm{l}=1,2, \ldots, \mathrm{m} ; \mathrm{E}_{\mathrm{ijkl}}$ represents the 1th observation of loading efficiency; $u$ represents the mean of each response variable; $i$ represents the ith effect of loading time; $j$ represents the jth effect of loading quantity; k represents the kth effect of number of logs loaded; eijkl means an error component that represents uncontrolled variability; $m$ represents the number of observations within each treatment. Meanwhile, the interaction factors between loading quantity and the number of logs loaded are also considered in the model.

Based on the result statistical analysis, the loading efficiency of the multifunctional skidding and loading machine is significantly different in the loading time $(P<0.001)$ and the loading quantity $(P<0.001)$. But there is no significant difference in loading efficiency and number of logs skidded $(P=0.037)$. After removing the variables which have no significant difference with the loading efficiency, the general linear model for correlation between the new loading efficiency of the skidding loader and the loading time and the loading quantity is $E=17.885-5.315 T+18.168 Q$, and $\mathrm{R}^{2}$ is 0.97 . From this model, we can find that the loading efficiency decreases as the skidding time increases, but increases as the loading quantity increases.

\subsubsection{Analysis on Loading Productivity}

Based on the data in Table 2, Formula (2) is used to calculate the log loading productivity of the multifunctional skidding and loading machine. The result is listed as below:

$$
P=\frac{(60 \times 6-40) \times 0.8 \times 0.602}{1.06+0.87+0.8+0.2}=52.6 \mathrm{~m}^{3} / \text { machine } \cdot \text { shift }
$$

From the result, we can find that the loading productivity of the multifunctional skidding and loading machine studied and designed can meet the requirements of forest felling operation.

\section{Conclusions}

The experimental prototype of the multifunctional skidding and loading machine was used to carry out the skidding, loading and obstacle clearing operation test in Daxi Forest Farm, Linjiang Forestry Bureau, Jilin Forest Industry Group, and the quantitative analysis on the skidding and loading efficiency and the skidding and loading productivity of the skidding and loading machine was made. The average skidding efficiency is $7 \mathrm{~m}^{3} \cdot \mathrm{h}^{-1} \cdot \operatorname{trip}^{-1}$, and the average loading efficiency is $16.45 \mathrm{~m}^{3} \cdot \mathrm{h}^{-1} \cdot$ time $^{-1}$, and the skidding productivity is 29.62 $\mathrm{m}^{3} /$ machine shift, and the loading productivity is $56.2 \mathrm{~m}^{3} /$ machine $\cdot$ shift. The result of regression analysis shows that the skidding efficiency decreases as the skidding distance and the skidding time increase, and increases as the loading quantity per trip increases, but the trend is not obvious. In addition, the sample size and the effect variables are relatively small, so the accuracy of prediction and estimation may be reduced when carrying out the regression analysis. Therefore, in order to better predict the skidding and loading efficiency of the skidding and loading machine, a big sample size and more effect variables are needed. The correlation analysis shows that the correlations between the skidding efficiency and the skidding distance, the skidding time, the skidding quantity per trip and the skidding are obviously different, and the correlation between the loading efficiency and the loading time and the loading quantity variables are obviously different. 
The data of this test shows that the design multifunctional skidding and loading machine well adapts to the complex and changeable timber production operation conditions of the forest area in the Northeast of China, and the machine has the high skidding and loading productivity and can meet the operation requirements of forest area. In combination with the results of this study, we can conclude that shortening the total skidding time, the skidding distance and reasonably determining the skidding quantity per trip can improve the skidding efficiency, and shortening the loading time especially the grabbing time can improve the loading efficiency. In addition, the designed multifunctional skidding and loading machine also has the function of obstacle clearing, and the efficiency is also very high.

\section{Acknowledgements}

The authors would like to acknowledge the support of the Fundamental Research Funds for the Central Universities (Grant No. DL13BB10) and the Special Scientific Research Funds for Forest Non-profit Industry (Grant No. 201104007).

\section{References}

[1] X. B. Dong, J. Q. Fu, J. F. Sun, Y. F. Qi, X. C. Yang, M. K. Xu, B. P. Wang and X. Z. Wang, "Comparison between tractor skidding and animal skidding of artificial forest", Journal of Northeast Forestry University, vol. 33, no. 6, (2005), pp. 116-118.

[2] S. B. Song, "Brief discussion about reform of loading technology in felling area", Teaching of Forestry Regions, vol. 123, no. 6, (2007), pp. 120-121.

[3] D. H. Liu, "The discussion of skidding ways in Heilongjiang state-owned forest region", Heilongjiang Science and Technology Information, no. 4, (2010), pp. 14.

[4] J. B. Zhao and J. H. He, "The basic conditions and analysis of the afforesting tractors and the log skidders in China”, Forestry Machinery \& Woodworking Equipment, vol. 35, no. 7, (2007), pp. 15-16.

[5] K. Wu, "The changes and development trend of the skidding way in Heilongjiang forest inductry region", Science and technology innovation and Application, no. 19, (2012), pp. 255.

[6] W. Q. Zhang, Y. K. Cao and M. Y. Jiang, "Simple analysis on factors influencing tractor skidding efficiency", Forest Harvesting and Transportation Science, no. 8, (1990), pp. 15-18.

[7] L. H. Wang, G. F. Wang and Y. E. Yan, "The dynamic analysis for operation efficiency of ground skidding system influenced by uncontrolable factors", Journal of Northeast Forestry University, vol. 21, no. 3, (1993), pp. 34-38.

[8] J. Y. Shi, "Harvesting and transportation technology and development of Chinese forest industry", Press of Northeast Forestry University, Harbin (1998).

\section{Authors}

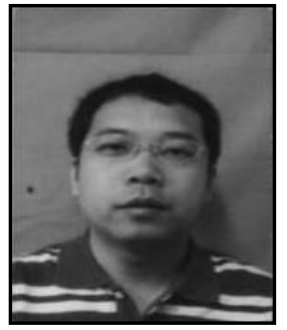

Wenshu Lin, earned a B.E. degree and a M.S. degree in Forest Engineering from Northeast Forestry University, Harbin, P. R. China in 2003 and 2005, respectively. In 2011, he received a Ph.D. degree in Forest Resources Science from West Virginia University, USA. He is a Member of Forest Products Society and Society of Wood Science and Technology. Dr. Lin had several publications in esteemed journals such as Forest Products Journal, Wood and Fiber Science, and Computers and Electronics in Agriculture. Currently, he is an associate professor at Northeast Forestry University, Harbin, P. R. China. His major research interests include nondestructive testing and evaluation of wood, wood utilization and production improvement, and computer simulation and system modeling. 


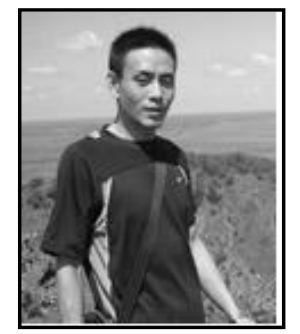

Deling Yang, earned his M.S. degree and Ph.D. degree in Forest Engineering from Northeast Forestry University, Harbin, P. R. China in 2006 and 2013, respectively. Currently, he is an engineer at Northeast Forestry University, Harbin, P. R. China. His major research interests include forestry machinery and Engineering ropeway. In recent five years, he has published five papers, leaded two projects, and joined four research programs including the Special Scientific Research Funds for Forest Nonprofit Industry and the other Research Funds.

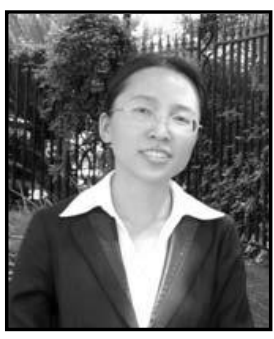

Jinzhuo Wu, earned her B.E. degree and M.S. degree in Forest Engineering from Northeast Forestry University, Harbin, P. R. China in 2003 and 2005, respectively. In 2010, she obtained her Ph.D. degree in Forest Resources Science from West Virginia University, USA. She is a Member of Forest Products Society. Dr. Wu had several publications in esteemed journals such as Forest Products Journal, Wood and Fiber Science, Canadian Journal of Forest Research, and Journal of Agriculture and Resources Economics.

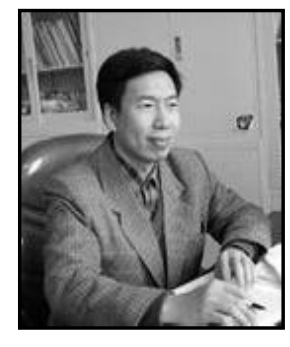

Lihai Wang, is a professor and executive vice president of the Graduate School, Northeast Forestry University, Harbin, China. He holds BS, MS and PhD degrees in Forest Logging and Transportation Engineering, all from Northeast Forestry University. He has focused his research in several areas, including ecological forest operations, transportation and logistics engineering in forestry, forest products testing and the development of innovative wood products. Dr. Wang has published more than 150 technical articles in refereed journals, and holds six patents. He is a respected technical leader and administrator, holding key leadership positions with the International Union of Forestry Research Organizations (IUFRO), Chinese Society of Forestry, International Journal of Forest Engineering, Forest Engineering National Experiment and Teaching Demonstration Center, and the Heilongjiang Provincial Laboratory. 